\title{
Parry-Romberg Syndrome Associated with Localized Scleroderma
}

\author{
Jelena Maletic Vassiliki Tsirka Panos loannides \\ Dimitrios Karacostas Nikolaos Taskos \\ B Department of Neurology, AHEPA University Hospital, Thessaloniki, Greece
}

\section{Key Words}

Parry-Romberg syndrome - Localized scleroderma - Neurocutaneous disease $\cdot$ Morphea

\begin{abstract}
Parry-Romberg syndrome is a rare neurocutaneous disorder of unknown origin. It is characterized by progressive facial hemiatrophy and frequently overlaps with a condition known as linear scleroderma 'en coup de sabre'. Neurological involvement is frequently described in these patients, including migraine, facial pain and epilepsy, which represent the commonest neurological conditions, sometimes associated with brain abnormalities ipsilaterally to the skin lesions. We present a case of Parry-Romberg syndrome with neurological involvement in a patient with diagnosed localized scleroderma (morphea).
\end{abstract}

\section{Introduction}

Parry-Romberg syndrome (PRS) is a rare neurocutaneous disorder of unknown origin first described by Parry in 1825 and Romberg in 1846. It is characterized by progressive facial hemiatrophy of the skin, subcutaneous tissue and sometimes the adjacent craniofacial bones, sparing facial muscles, that affects mainly the maxillary region but may extend to the chin and forehead [1]. The onset is subtle, affecting mostly women before the age of 20 years, and disease usually progresses over 2 to 20 years and then enters a stable phase. Patients with early onset tend to be more severely affected $[2,3]$.

PRS can be a distinct disease entity but frequently overlaps with a condition known as linear scleroderma 'en coup de sabre'. Scleroderma 'en coup de sabre' is a linear localized form of morphea, affecting the frontoparietal scalp and forehead in stripe-like sclerotic plaques. The skin of this area appears hard, hyperpigmented, shiny and with alopecia. The differential diagnosis between progressive facial hemiatrophy and linear scleroderma is mainly based on clinical and histopathological findings. Extracutaneous changes are associated both with linear scleroderma and PRS [4]. 


\begin{tabular}{l|l|l|l} 
Case Reports in & $\begin{array}{l}\text { Case Rep Neurol 2010;2:57-62 } \\
\text { Dol: } 10.1159 / 000314927\end{array}$ & Published online: June 1, 2010 & $\begin{array}{l}\text { ○ 2010 S. Karger AG, Basel } \\
\text { ISSN 1662-680X } \\
\text { www.karger.com/crn }\end{array}$ \\
\hline
\end{tabular}

Hemiatrophy of the arm, trunk or leg ipsilaterally or contralaterally may be present in these patients, while some may have tongue atrophy and dental abnormalities. There are reports regarding ocular features, such as enophthalmos, uveitis and heterochromia, and participation of skin and hair disorders including hyperpigmentation, vitiligo and alopecia. Patients also report frequent hemimasticatory spasms [1].

Neurological disorders are more frequent in patients with upper face and scalp involvement. Migraine and facial pain (trigeminal neuralgia) are the commonest neurological conditions, and epilepsy has been described in $10 \%$ of the patients, sometimes associated with brain abnormalities ipsilaterally to the skin lesions [2, 4].

Neuroimaging findings when apparent may include hyperintense ipsilateral cortical and subcortical lesions, intraparenchymal calcifications and localized cerebral hemiatrophy, corresponding to the affected side. Patients with cerebral hemiatrophy may show continuous slowing and multifocal sharp waves during EEG recording $[5,6]$.

There is an ongoing debate on whether localized scleroderma and PRS are two different disorders or belong to the same disease spectrum. Here we present a case of a patient with a history of localized scleroderma who was referred to us because of neurological complications and was found to have progressive facial hemiatrophy as well.

\section{Case Report}

A 38-year-old white woman with an 8-year history of localized scleroderma diagnosed by biopsy and no previous neurological complaints was admitted to our department in order to investigate frequent headaches that she developed over the last 6 months. The headaches were constant, diffuse, with atypical migraine characteristics. The patient had a mild left facial hemiatrophy, jaw symptoms, including hemimasticatory spasms coexisting with linear scleroderma affecting the forehead 'en coup de sabre' (fig. 1) and sclerotic plaques on the lower back (fig. 2) and the neck area. The facial hemiatrophy had late onset and a progressive course. The neurological examination was unremarkable. She did not report any seizure-like symptoms or cognitive impairment.

The brain MRI did not reveal any abnormalities affecting the ipsilateral grey or white matter, but the EEG recording showed paroxysmal, slow, polymorphic, sharp activity of 4-5 Hz frequency, localized in the right temporal region.

The patient was treated with amitryptiline $25 \mathrm{mg}$.

\section{Discussion}

Progressive facial hemiatrophy (or PRS) and localized scleroderma 'en coup de sabre' are rare pathological entities of uncertain etiology, with a heterogenic spectrum of associated neurological complications.

The origin of PRS varies from face or body trauma $[2,7]$, especially in childhood onset disease [8], alteration of the sympathetic ganglion or trigeminal nerve [9], infections including Borrelia burgdorferi $[2,10,11]$, to autoimmune mechanisms. The latter is supported by the coexistence of PRS with other autoimmune disorders, such as thyroid disease, vitiligo, rheumatoid arthritis, ankylosing spondylitis and lupus erythematosus $[1$, 12] and by the elevated titers of one or more autoantibodies [13].

We present a case of a 38-year-old woman suffering from headaches with unusual characteristics regarding her age, with a known history of localized scleroderma and newly revealed progressive facial hemiatrophy. According to reports, females have a 
higher prevalence of both PRS and morphea with initial presentation in early childhood [14], but late onset, as in our case, is also described. The patient had left facial hemiatrophy with forehead involvement ('en coup de sabre') and left hemimasticatory spasms, which affect approximately one third of PRS patients [2]. Headache, the most frequent neurological presentation, was the reason of her referral to the neurological department. This is consistent with the general view that localized scleroderma predates the neurological symptoms by several years [13]. Although MRI did not reveal any structural brain lesions [15], her EEG findings had contralateral abnormal activity, without a clinical presentation of epilepsy.

The relationship between linear scleroderma and progressive facial hemiatrophy is not yet clearly understood. Although there are different diagnostic criteria based on distinct clinical and histopathological findings related to the different pathophysiological mechanisms attributed to these two entities [16], there are many reports about their coexistence and their common extracutaneous features. Sommer et al. [17] reported that $42 \%$ of the patients with PRS had also 'en coup de sabre' lesions. Blaszczyk et al. [6] also stress the close relationship of morphea and PRS based on their mutual central nervous system involvement. The same conclusion was drawn by Kister et al. [13]. Tollefson and Witman [4] confirmed these results, and they also reported that $36.6 \%$ of patients with linear scleroderma also had PRS. It was also described that biopsy specimens from PRS patients who did not have cutaneous sclerosis showed findings consistent with morphea.

Migraine and trigeminal neuralgia are the commonest neurological features of PRS with a frequency reaching $52 \%[1,2]$. There are reports associating these neurological symptoms with peripheral sympathetic nervous system or trigeminal nerve abnormalities $[11,12]$ and others support the presence of vascular dysgenesis [18-20].

PRS is generally considered as a self-limited disease and the need for treatment arises from the coexistence of localized scleroderma or other autoimmune disorders. In case of localized scleroderma, methotrexate and corticosteroids are the treatment of choice, while other immunosuppressant agents like cyclophosphamide, cyclosporine, D-penicillamine and hydroxychloroquine are used when more aggressive therapy is required [4, 21]. Reconstructive surgery, which includes fat injections, silicon implants, dermis-fat grafts, galeal flaps and bone and cartilage grafts, is beneficial in the cases of disfiguring facial atrophy $[7,22,23]$.

In conclusion, linear scleroderma and progressive facial hemiatrophy are closely related forms of cranial facial scleroderma with common neurological manifestations, but their sole existence in some cases and their different histopathological characteristics and treatment approach make the definite thesis of disease overlapping still part of a continuous debate. 


\begin{tabular}{l|l|l|l} 
Case Reports in & $\begin{array}{l}\text { Case Rep Neurol 2010;2:57-62 } \\
\text { D0I: } 10.1159 / 000314927\end{array}$ & Published online: June 1, 2010 & $\begin{array}{l}\text { @ 2010 S. Karger AG, Basel } \\
\text { ISSN 1662-680X } \\
\text { www.karger.com/crn }\end{array}$ \\
\hline
\end{tabular}

Fig. 1. Presence of linear morphea 'en coup de sabre' affecting the forehead.

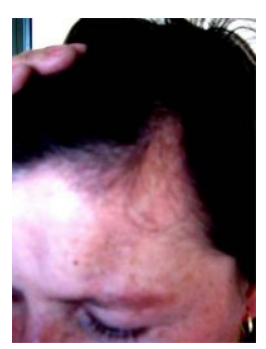

Fig. 2. Sclerotic plaque localized on the lower back.

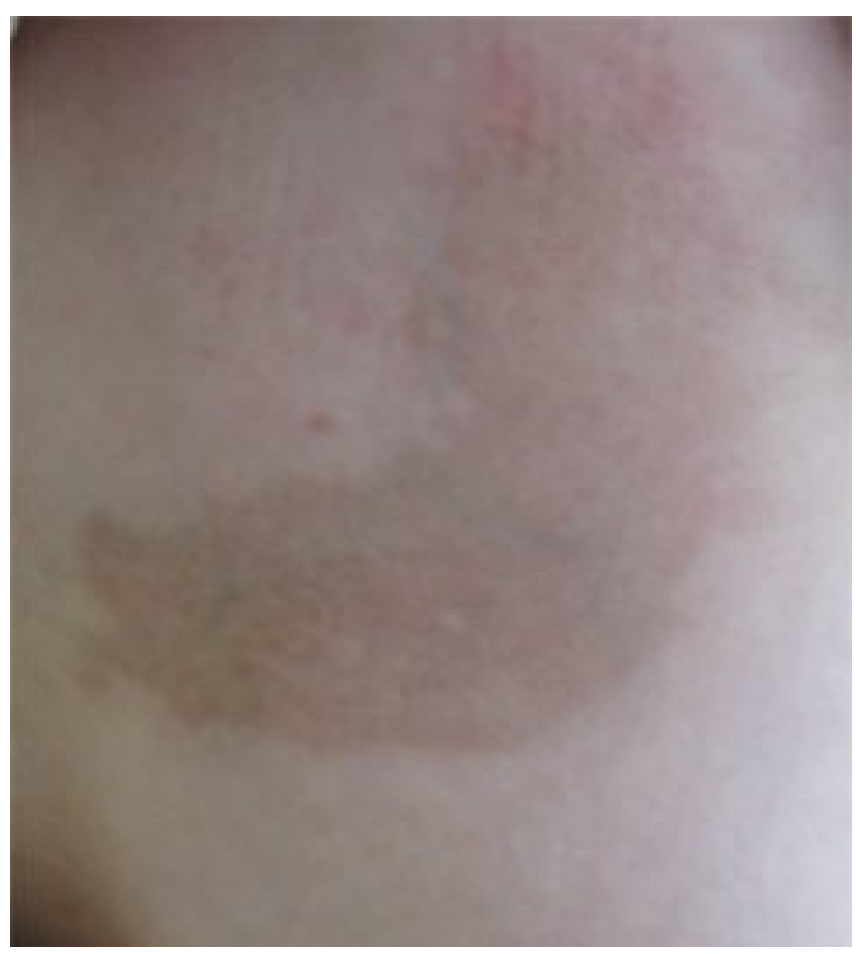




\begin{tabular}{l|l|l|l} 
Case Reports in & $\begin{array}{l}\text { Case Rep Neurol 2010;2:57-62 } \\
\text { Dol: } 10.1159 / 000314927\end{array}$ & Published online: June 1, 2010 & $\begin{array}{l}\text { ○ 2010 S. Karger AG, Basel } \\
\text { ISSN 1662-680X } \\
\text { www.karger.com/crn }\end{array}$ \\
\hline
\end{tabular}

\section{References}

1 Stone J: Parry-Romberg Syndrome. Practical Neurology 2006;6:185-188.

2 Stone J: Parry-Romberg syndrome: a global survey of 205 patients using the Internet. Neurology 2003;61:674-676.

-3 Pichiecchio A, Uggetti C, Grazia Egitto M, Zappoli F: Parry-Romberg syndrome with migraine and intracranial aneurysm. Neurology 2002;59:606-608.

-4 Tollefson MM, Witman PM: En coup de sabre morphea and Parry-Romberg syndrome: a retrospective review of 54 patients. J Am Acad Dermatol 2007;56:257-263.

5 Carreño M, Donaire A, Barceló MI, Rumià J, Falip M, Agudo R, Bargalló N, Setoain X, Boget T, Raspall A, Pintor L, Ribalta T: Parry Romberg syndrome and linear scleroderma in coup de sabre mimicking Rasmussen encephalitis. Neurology 2007;68:1308-1310.

6 Blaszczyk M, Królicki L, Krasu M, Glinska O, Jablonska S: Progressive facial hemiatrophy: central nervous system involvement and relationship with scleroderma en coup de sabre. J Rheumatol 2003;30:1997-2004.

7 Slimani S, Hounas F, Ladjouze-Rezig A: Multiple linear sclerodermas with a diffuse Parry-Romberg syndrome. Joint Bone Spine 2009;76:114-116. Epub 2008 Nov 6.

-8 Vancheeswaran R, Black CM, David J, Hasson N, Harper J, Atherton D, Trivedi P, Woo P: Childhood-onset scleroderma: is it different from adult-onset disease. Arthritis Rheum 1996;39:1041-1049.

-9 Wolf SM, Verity MA: Neurological complications of progressive facial hemiatrophy. Neurol Neurosurg Psychiatry 1974;37:997-1004.

10 Lewkonia RM, Lowry RB: Progressive hemifacial atrophy (Parry-Romberg syndrome) - report with review of genetics and nosology. Am J Med Genet 1983;14:385-390.

11 Lonchampt P, Emile J, Pelier-Cady MC, Cadou B, Barthelaix A: Central sympathetic dysregulation and immunological abnormalities in a case of progressive facial hemiatrophy (Parry-Romberg disease). Clin Auton Res 1995;5:199-204.

12 Menascu S, Padeh S, Hoffman C, Ben-Zeev B: Parry-Romberg syndrome presenting as status migrainosus. Pediatr Neurol 2009;40:321-323.

13 Kister I, Inglese M, Laxer RM, Herbert J: Neurologic manifestations of localized scleroderma: a case report and literature review. Neurology 2008;71:1538-1545.

14 Peterson LS, Nelson AM, Su WP, Mason T, O'Fallon WM, Gabriel SE: The epidemiology of morphea (localized scleroderma) in Olmsted County 1960-1993. J Rheumatol 1997;24:73-80.

15 Holland KE, Steffes B, Nocton JJ, Schwabe MJ, Jacobson RD, Drolet BA: Linear scleroderma en coup de sabre with associated neurologic abnormalities. Pediatrics 2006;117:e132-e136.

-16 Orozco-Covarrubias L, Guzmán-Meza A, Ridaura-Sanz C, Carrasco Daza D, Sosa-de-Martinez C, Ruiz-Maldonado R: Scleroderma 'en coup de sabre' and progressive facial hemiatrophy. Is it possible to differentiate them? J Eur Acad Dermatol Venereol 2002;16:361-366.

17 Sommer A, Gambichler T, Bacharach-Buhles M, von Rothenburg T, Altmeyer P, Kreuter A: Clinical and serological characteristics of progressive facial hemiatrophy: a case series of 12 patients. J Am Acad Dermatol 2006;54:227-233.

18 Derex L, Isnard H, Revol M: Progressive facial hemiatrophy with multiple benign tumors and hamartomas. Neuropediatrics 1995;26:306-309.

19 Sagild JC, Alving J: Hemiplegic migraine and progressive hemifacial atrophy. Ann Neurol 1985; 17:620.

20 Woolfenden AR, Tong DC, Norbash AM, Albers GW: Progressive facial hemiatrophy: abnormality of intracranial vasculature. Neurology 1998;50:19151917.

-21 Holland KE, Steffes B, Nocton JJ, Schwabe MJ, Jacobson RD, Drolet BA: Linear scleroderma en coup de sabre with associated neurologic abnormalities. Pediatrics 2006;117:e132-e136. 


\begin{tabular}{l|l|l|l} 
Case Reports in & $\begin{array}{l}\text { Case Rep Neurol 2010;2:57-62 } \\
\text { D01: } 10.1159 / 000314927\end{array}$ & Published online: June 1, 2010 & $\begin{array}{l}\text { @ 2010 S. Karger AG, Basel } \\
\text { ISSN 1662-680X } \\
\text { www.karger.com/crn }\end{array}$ \\
\hline
\end{tabular}

22 Guerrerosantos J, Guerrerosantos F, Orozco J: Classification and treatment of facial tissue atrophy in Parry-Romberg disease. Aesthetic Plast Surg 2007;31:424434.

-23 Iñigo F, Jimenez-Murat Y, Arroyo O, Fernandez M, Ysunza A: Restoration of facial contour in Romberg's disease and hemifacial microsomia: experience with 118 cases. Microsurgery 2000;20:167-172. 